\title{
DEPOIS DOS 35 ANOS, QUAIS AS INTENÇÕES DE FECUNDIDADE DOS SUL-EUROPEUS?
}

\section{Rita Freitas}

Cidehus, Universidade de Évora, Évora, Portugal

Maria Filomena Mendes

Cidehus, Universidade de Évora, Évora, Portugal

Andreia Maciel

Cidehus, Universidade de Évora, Évora, Portugal

\begin{abstract}
Resumo Sendo a baixa fecundidade comum na Europa do Sul, e considerando que nas últimas décadas tanto homens como mulheres têm vindo a adiar a entrada na parentalidade, interessa estudar os determinantes das intenções de fecundidade. Em particular, dos sul-europeus com mais de 35 anos, idade a partir da qual se considera que aqueles que não têm filhos, ou que têm apenas um, se encontram a adiar os seus projetos de fecundidade. Os resultados mostram que perceções negativas em relação à situação do país são inibidoras no processo da tomada de decisão de ter filhos, especialmente o segundo filho. Este trabalho remete para a importância de considerar valores e expectativas dos indivíduos em relação à sua vida e à situação do país como preditores do comportamento reprodutivo.
\end{abstract}

Palavras-chave: baixa fecundidade, adiamento da fecundidade, valores e atitudes, Europa do Sul.

Abstract Because low fertility is common in Southern European countries and considering that in recent decades both men and women have been postponing their fertility projects, it is of our interest to study the determinants of reproductive decision-making. Particularly, of Southern Europeans older than 35, age from which it is considered that those who have no children, or that have only one child, have postponed their fertility projects. The findings show that negative perceptions about the situation of the country inhibit the process of having a child, specially the second one. This paper reports to the importance of considering values and perceptions of individuals about their lives and the situation of the country as predictors of fertility behaviour.

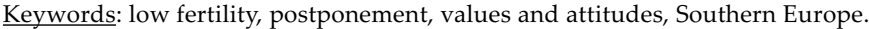

Résumé Depuis quelques décennies, alors que le taux de fécondité est bas dans les pays du sud de l’Europe, les femmes comme les hommes tendent à repousser l'âge de la parentalité. Cet article étudie les facteurs déterminants des intentions de fécondité, en particulier des sud-européens de plus de 35 ans, l'âge à partir duquel on considère que ceux qui n'ont pas d'enfants ou qui n'en ont qu'un seul repoussent à plus tard leurs projets de fécondité. Les résultats montrent que les perceptions négatives sur la situation du pays sont inhibitrices dans la prise de décision d'avoir des enfants, en particulier s'il s'agit du deuxième enfant. Ce travail souligne combien les valeurs et les attentes des individus concernant leur vie et la situation du pays sont révélatrices de leur comportement reproductif.

Mots-clés: basse fécondité, report de la fécondité, valeurs et attitudes, Europe du sud.

Resumen Siendo común la baja fecundidad en Europa del Sur y considerando que en las últimas décadas tanto hombres como mujeres han venido atrasando la entrada en la parentalidad, interesa estudiar los determinantes de las intenciones de fecundidad. En particular, de los sur-europeos con más de 35 años, edad a partir de la cual se considera que aquellos que no tienen hijos, o que tienen apenas uno, se encuentran atrasando sus proyectos de fecundidad. Los resultados muestran que percepciones negativas en relación a la situación del país son inhibidoras en el proceso de la toma de decisión de tener hijos, especialmente el segundo hijo. Este trabajo confirma la importancia de considerar valores y expectativas de los individuos en relación a su vida y a la situación del país como predictores del comportamiento reproductivo.

Palabras-clave: baja fecundidad, aplazamiento de la fecundidad, valores y actitudes, Europa del Sur. 


\section{Introdução}

A baixa fecundidade é atualmente uma das grandes preocupações de alguns países europeus, incluindo os do Sul. Portugal não é exceção, pois regista um dos níveis de fecundidade mais baixos da Europa e do mundo. Em 2013, o índice sintético de fecundidade (ISF) foi igual a 1,21 filhos por mulher, e desde 1982 aquele indicador passou a situar-se abaixo do limiar da substituição das gerações (2,1 filhos por mulher), e em 1994 ficou, pela primeira vez, abaixo de 1,5 filhos por mulher. De certa forma, o aumento do número de mulheres e homens que não têm filhos e o adiamento da entrada na parentalidade têm contribuído para os baixos valores dos índices de fecundidade observados (Morgan, 1991; Sobotka, 2008). De facto, nos últimos anos, o adiamento no nascimento do primeiro e, consequentemente, do segundo filho tem sido um comportamento comum entre os portugueses (Cunha, 2012; Mendes, 2012), sendo, em 2014, 31,5 anos a idade média em que as mulheres tiveram filhos, e a idade média com que tiveram o primeiro filho foi aos 30,0 anos. A proximidade entre estas idades sugere que as mulheres portuguesas tendem a ter apenas um filho e tardiamente.

Nos restantes países do Sul da Europa também se tem verificado o adiamento dos projetos de fecundidade. Efetivamente, segundo dados do Eurostat de 2014, na Grécia as mulheres tiveram o primeiro filho, em média, aos 30,0 anos, em Espanha aos 30,6 anos e em Itália, o valor estimado foi de 30,7 anos.

Apesar do notório adiamento dos projetos de fecundidade, pouco sabemos sobre as intenções reprodutivas dos sul-europeus depois dos 35 anos, idade a partir da qual a decisão de ter um filho ou de transitar para o segundo filho pode começar a ser comprometida por limites biológicos, bem como pela disposição de voltar a experienciar a parentalidade.

Sendo a idade referida na literatura como um fator fundamental para explicar as intenções reprodutivas, nos países do Sul da Europa, poderá o adiamento da entrada na parentalidade (após os 35 anos) tornar-se um fator "inibidor" no processo de transição para a parentalidade e um fator potenciador da "possibilidade de renúncia" à transição para o segundo filho? A ser verdade, o adiamento da idade de nascimento do primeiro filho pode explicar não apenas o quão tardio pode ser o nascimento do segundo, mas também a redução do número de filhos das famílias. Deste modo, o contínuo adiamento pode afetar quer a intensidade da fecundidade, o número de filhos tidos ( 0 ou 1 - com claro aumento da probabilidade de ter apenas 1), quer o seu calendário (aumento da idade em que se tem os filhos, o primeiro e o segundo, ou seja, um duplo adiamento).

Para além do fator idade e das características sociodemográficas habitualmente estudadas na literatura (género, nível de escolaridade, etc.) consideramos que os valores (em particular o número de filhos ideal para uma família), assim como as perceções e as expectativas dos indivíduos podem ser decisivas para as intenções de fecundidade, em particular daqueles que chegaram aos 35 anos sem filhos ou com apenas um filho. Se estas perceções e/ou expectativas são negativas tornam-se também inibidoras (ainda mais em tempo de crise nos países da Europa do Sul), tanto da intensidade - quantum - como do calendário da fecundidade - tempo. 
Considerando algumas características sociodemográficas, valores, perceções e expectativas, pretendemos identificar quais os fatores que distinguem aqueles indivíduos que, após os 35 anos, tencionam manter-se sem filhos ou com apenas um filho, ou seja, pretendemos explicar o duplo adiamento da fecundidade. Adicionalmente, pretendemos perceber se os valores, perceções e expectativas dos sul-europeus têm ou não uma maior relevância face às características sociodemográficas, e se, por sua vez, estes fatores assumem uma maior importância quando a decisão em causa é permanecer sem filhos ou com um único filho.

Para atingir os objetivos acima propostos, primeiro, começamos por fazer uma revisão da literatura sobre a tomada de decisão relativa aos projetos de fecundidade (secção 2). Em seguida, fazemos uma descrição dos dados e metodologia (secção 3) e, posteriormente, apresentamos os resultados obtidos (secção 4). Por fim, na secção 5 discutimos os resultados mais relevantes do estudo e apresentamos algumas considerações finais.

\section{Da intenção ao comportamento}

Nesta secção, faremos uma breve revisão da teoria do comportamento planeado (Ajzen, 1991; Ajzen e Klobas, 2013), com o objetivo de a enquadrar no contexto das intenções e decisões de fecundidade. Segundo esta teoria, a intenção de ter ou não um filho é vista como um precursor do comportamento, e a sua formulação é influenciada por três grupos de fatores: (1) atitudes pessoais (positivas ou negativas) em relação ao comportamento, sendo ter ou não ter um filho o comportamento em causa no contexto da fecundidade; (2) normas subjetivas, i.e., perceção da pressão social em relação ao comportamento - contextos sociais e familiares, podendo comportamentos exibidos por familiares e amigos incentivar os indivíduos a comportarem-se de forma semelhante; (3) perceção de controlo do comportamento, ou seja, perceção da possibilidade de ter um filho (Ajzen e Klobas, 2013).

Esta teoria, assume que o comportamento (ter um filho) é um produto de intenções comportamentais, que, por sua vez, são produtos das atitudes, das normas subjetivas e da perceção de controlo. As atitudes refletem as crenças e os valores pessoais, e as normas subjetivas refletem a posição do indivíduo em relação aos seus pares, e a ponderação destas atitudes e normas resulta numa intenção que pode ser vista como um determinante próximo do comportamento (figura 1).

Segundo Ajzen e Klobas (2013), quanto mais favoráveis forem a atitude, a norma subjetiva e a perceção de controlo, mais provável é que uma pessoa venha a formar a intenção de ter um filho. Considerando que os indivíduos têm controlo do seu comportamento, espera-se que estas intenções resultem em ter ou não um filho. Deste modo, espera-se que o controlo em relação ao comportamento seja um moderador do efeito da intenção no comportamento. No entanto, é difícil prever todos os fatores que influenciam o controlo sobre um 


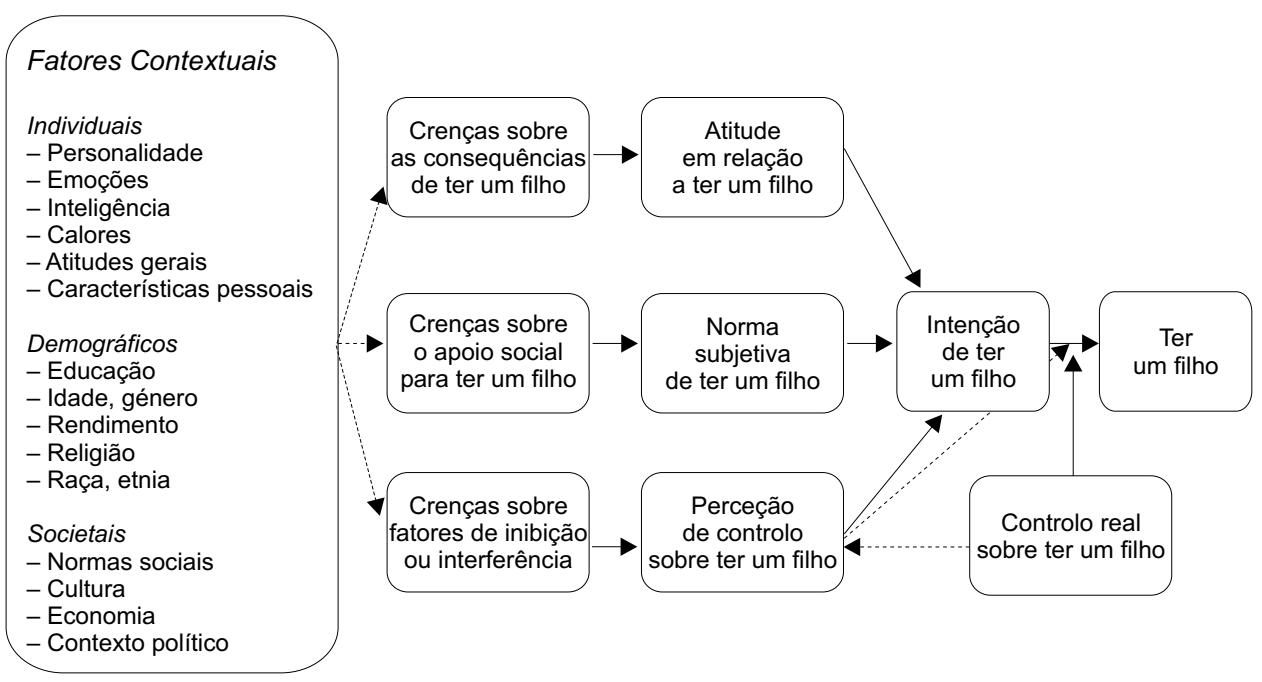

Figura 1 Teoria do comportamento planeado aplicada às decisões de fecundidade

Fonte: Figure 1, Ajzen e Klobas (2013: 206).

determinado comportamento, por isso é preferível usar um proxy de controlo, assumindo que as perceções de controlo refletem bem o "verdadeiro" controlo (figura 1).

Simultaneamente, a figura 1 mostra como é que a teoria do comportamento planeado pode ajudar a prever o papel de variáveis como nacionalidade, idade, sexo, paridade, educação, rendimento, religião, personalidade, valores e atitudes individuais, entre outras, na intenção de ter ou não um filho.

Ainda segundo Ajzen e Klobas (2013), a aplicação da teoria do comportamento planeado pode fornecer informações muito úteis sobre as decisões de fecundidade, permitindo, assim, melhorar o conhecimento desta tomada de decisão. Ao estudar crenças e normas subjetivas individuais em relação ao comportamento, ou seja, conhecendo as intenções de fecundidade dos indivíduos, podemos identificar considerações importantes que influenciam a decisão de ter um filho. Esta informação poderá também servir de guia para a adoção de políticas desenhadas para encorajar os casais a ter os filhos que desejam.

\section{Dados e metodologia}

Usando dados europeus sobre as intenções de fecundidade (Eurobarómetro, 2011) e recorrendo à construção de modelos de regressão logística, pretende-se encontrar os fatores que explicam o duplo adiamento da fecundidade, i.e., o adiamento no nascimento quer do primeiro, quer do segundo filho. Primeiro, pretende-se distinguir os determinantes da intenção de permanecer sem filhos (infecundidade 
permanente) depois dos 35 anos, comparando estes indivíduos com aqueles que não tendo filhos ainda tencionam tê-los (infecundidade temporária). Em seguida, pretende-se descobrir os fatores que influenciam a intenção de permanecer com apenas um filho depois dos 35 anos, comparando estes indivíduos com aqueles que ainda pretendem transitar para o segundo filho.

No ajustamento destes modelos, considerámos não apenas os residentes em Portugal, mas também os residentes em Espanha, Itália e Grécia. Por se tratar de uma (in)fecundidade tardia, apenas incluímos os indivíduos com idades entre os 36 e os 54 anos. Para estudar a infecundidade permanente recorremos a uma amostra de 244 indivíduos, e no estudo do filho único a 299 observações. Em ambos os modelos considerámos algumas variáveis de caracterização presentes na base de dados do Eurobarómetro, tais como a idade, o sexo, o país e a dimensão da área de residência, a situação conjugal, o nível de escolaridade do próprio, a situação de emprego, o número ideal de filhos para uma família, e variáveis relacionadas com as perceções e expectativas dos indivíduos em relação à sua vida e à situação do país (quadro 1).

Considerando que a amostra do Eurobarómetro foi selecionada a partir de um esquema de amostragem complexo (o qual permite obter amostras representativas dos diferentes países) e de forma a obter estimativas das variâncias mais precisas e não enviesadas, para os valores totais e proporções apresentados, assim como no ajuste dos modelos de regressão logística, incluímos os pesos relativos aos países analisados. Quanto aos modelos escolhidos, estes têm uma grande aplicabilidade quando se pretende ajustar um modelo parcimonioso que permita descrever a relação entre uma variável resposta e um conjunto de variáveis explicativas. Porém, o que distingue um modelo de regressão logística é o facto de a variável resposta ser dicotómica, como é o caso das variáveis resposta deste estudo.

O modelo de regressão logística pode ser escrito através da expressão:

$$
\pi(X)=E(Y \mid X)=\frac{1}{1+e^{-\left(\beta_{0}+\beta_{1} X_{1}+\beta_{2} X_{2}+\ldots+\beta_{p} X_{p}\right)}}, \text { onde } \pi(X)=E(Y \mid X)
$$

que representa a média da variável resposta $Y$ condicionada aos valores das $p$ variáveis explicativas, tal que $X=\left(X_{1}, X_{2}, \ldots, X_{n}\right)$.

O ajuste destes modelos foi efetuado com recurso aos pacotes survey, rms, $m f p$, EPI e epiR do programa R Project (R Core Team, 2012). Para ajustar os modelos seguimos a estratégia definida por Hosmer e Lemeshow (2013), e a significância das variáveis e das interações foi testada recorrendo ao teste de Wald modificado. A adequabilidade do ajustamento foi feita recorrendo aos testes de bondade de ajustamento de Hosmer e Lemeshow e de Cessie-van Houwelingen, e a capacidade discriminativa foi avaliada pelo valor AUC (area under the curve) da curva ROC (receiver operating characteristic). 
Quadro 1 Distribuição das variáveis usadas na análise multivariada, por paridade (\%)

\begin{tabular}{|c|c|c|c|c|}
\hline Variáveis & & Zero filhos & & Um filho \\
\hline $\begin{array}{l}\text { Idade (média, sd) } \\
\text { Mulheres } \\
\text { Homens } \\
\text { Portugal } \\
\text { Espanha } \\
\text { Itália } \\
\text { Grécia } \\
\text { Reside em área rural ou vila } \\
\text { Reside em pequena ou média cidade } \\
\text { Reside em grande cidade } \\
\text { Casado } \\
\text { Vive com companheiro } \\
\text { Solteiro } \\
\text { Divorciado ou separado } \\
\text { Até ensino básico } \\
\text { Secundário } \\
\text { Superior } \\
\text { Tem emprego } \\
\text { Não tem emprego } \\
\text { Ideal: menos de } 2 \\
\text { Ideal: } 2 \\
\text { Ideal: mais de } 2 \\
\text { Globalmente satisfeito com a vida que tem } \\
\text { Globalmente não satisfeito com a vida que tem } \\
\text { Globalmente nada satisfeito com a vida que tem } \\
\text { Melhores expectativas em relação à sua vida em geral } \\
\text { Mesmas expectativas em relação à sua vida em geral } \\
\text { Piores expectativas em relação à sua vida em geral }\end{array}$ & & $\begin{array}{l}43,2(5,3) \\
57 \\
43 \\
19 \\
23 \\
29 \\
29 \\
29 \\
47 \\
24 \\
33 \\
20 \\
42 \\
5 \\
26 \\
54 \\
20 \\
85 \\
25 \\
36 \\
52 \\
12 \\
66 \\
24 \\
10 \\
20 \\
54 \\
26\end{array}$ & & $\begin{array}{c}44,3(5,5) \\
53 \\
47 \\
30 \\
22 \\
28 \\
20 \\
29 \\
51 \\
20 \\
72 \\
7 \\
5 \\
16 \\
35 \\
49 \\
16 \\
79 \\
21 \\
26 \\
63 \\
11 \\
71 \\
21 \\
8 \\
17 \\
53 \\
30 \\
\end{array}$ \\
\hline \multicolumn{5}{|l|}{ Sistema de saúde no país } \\
\hline $\begin{array}{l}\text { Boa avaliação | Melhores ou mesmas expectativas } \\
\text { Má avaliação | Piores expectativas } \\
\text { Sistema de pensões no país } \\
\text { Boa avaliação | Melhores ou mesmas expectativas } \\
\text { Má avaliação | Piores expectativas }\end{array}$ & $\begin{array}{l}51 \\
49 \\
23 \\
77\end{array}$ & $\begin{array}{l}61 \\
39 \\
41 \\
59\end{array}$ & $\begin{array}{l}55 \\
45 \\
19 \\
81\end{array}$ & $\begin{array}{l}65 \\
35 \\
48 \\
52\end{array}$ \\
\hline \multicolumn{5}{|l|}{ Subsídios a desempregados no país } \\
\hline $\begin{array}{l}\text { Boa avaliação | Melhores ou mesmas expectativas } \\
\text { Má avaliação | Piores expectativas }\end{array}$ & $\begin{array}{l}18 \\
82\end{array}$ & $\begin{array}{l}40 \\
60\end{array}$ & $\begin{array}{l}17 \\
83\end{array}$ & $\begin{array}{l}45 \\
55\end{array}$ \\
\hline \multicolumn{5}{|l|}{ Acesso à habitação no país } \\
\hline $\begin{array}{l}\text { Boa avaliação | Melhores ou mesmas expectativas } \\
\text { Má avaliação | Piores expectativas }\end{array}$ & $\begin{array}{l}14 \\
86\end{array}$ & $\begin{array}{l}47 \\
53\end{array}$ & $\begin{array}{l}11 \\
89\end{array}$ & $\begin{array}{l}43 \\
58\end{array}$ \\
\hline \multicolumn{5}{|l|}{ Situação económica do país } \\
\hline $\begin{array}{l}\text { Boa avaliação | Melhores ou mesmas expectativas } \\
\text { Má avaliação | Piores expectativas }\end{array}$ & $\begin{array}{r}7 \\
93 \\
\end{array}$ & $\begin{array}{l}37 \\
62 \\
\end{array}$ & $\begin{array}{r}6 \\
93 \\
\end{array}$ & $\begin{array}{l}41 \\
59\end{array}$ \\
\hline \multicolumn{5}{|l|}{ Situação de emprego do próprio } \\
\hline $\begin{array}{l}\text { Boa avaliação | Melhores ou mesmas expectativas } \\
\text { Má avaliação | Piores expectativas }\end{array}$ & $\begin{array}{l}59 \\
41\end{array}$ & $\begin{array}{l}72 \\
28\end{array}$ & $\begin{array}{l}60 \\
40\end{array}$ & $\begin{array}{l}74 \\
26\end{array}$ \\
\hline $\begin{array}{l}\text { Situação financeira do agregado familiar } \\
\text { Boa avaliação | Melhores ou mesmas expectativas } \\
\text { Má avaliação | Piores expectativas }\end{array}$ & $\begin{array}{l}59 \\
41\end{array}$ & $\begin{array}{l}67 \\
33\end{array}$ & $\begin{array}{l}42 \\
58\end{array}$ & $\begin{array}{l}68 \\
32\end{array}$ \\
\hline $\begin{array}{l}\text { Situação de emprego no seu país } \\
\text { Boa avaliação | Melhores ou mesmas expectativas } \\
\text { Má avaliação | Piores expectativas }\end{array}$ & $\begin{array}{r}7 \\
93\end{array}$ & $\begin{array}{l}40 \\
60\end{array}$ & $\begin{array}{r}7 \\
93\end{array}$ & $\begin{array}{l}40 \\
60\end{array}$ \\
\hline
\end{tabular}

Nota: Para as variáveis relativas às expectativas agrupámos as categorias "melhores" e "na mesma" devido ao reduzido número de observações da primeira categoria. 


\section{Análise descritiva}

Aqueles que pretendem permanecer infecundos depois dos 35 anos correspondem a $45 \%$ dos residentes na Europa do Sul. Já os que pretendem permanecer com um único filho representam $77 \%$ da população que tem apenas um filho, nas idades superiores aos 35 anos.

Ao analisarmos a idade destes indivíduos, pelas suas intenções de fecundidade, concluímos que, para aqueles que não têm filhos, os que não pretendem tê-los são mais velhos do que os que ainda tencionam ter pelo menos um filho. O mesmo se verifica quando a intenção em causa é transitar ou não para o segundo filho. Dos que não pretendem transitar para a parentalidade ou para o segundo filho, a maioria tem até 45 ou 46 anos, respetivamente, enquanto a maioria dos que pretendem ter (mais) filhos tem até 38 e 39 anos, respetivamente.

Analisando a figura 2, concluímos que, a partir dos 35 anos, a maioria dos portugueses, espanhóis e italianos pretendem manter-se sem filhos ou com apenas um. No entanto, são os portugueses que se destacam, seja quando a intenção em causa é permanecer sem filhos (75\%) ou com um único filho (92\%). Em oposição, destacamos as intenções reprodutivas dos gregos, dos quais a maioria $(65 \%)$ ainda pretende vir a ter pelo menos um filho.

Depois dos 35 anos, a maioria das mulheres pretende permanecer sem filhos $(66 \%)$ ou com apenas um filho $(80 \%)$. O mesmo se verifica para os homens com mais de 35 anos, porém a proporção daqueles que não pretendem transitar para a parentalidade ou para o segundo filho é ligeiramente inferior, $52 \%$ e $74 \%$, respetivamente.

O nível de escolaridade dos residentes na Europa do Sul parece ser um fator diferenciador das intenções de fecundidade. De uma forma geral, quanto maior o nível de escolaridade, menor é a proporção de indivíduos que não pretendem ter (mais) filhos (figura 2). A exceção ocorre entre aqueles que não têm filhos, sendo mais elevada a proporção dos que pretendem manter-se sem filhos para aqueles que possuem o secundário (65\%) do que para os que possuem um nível de escolaridade inferior (63\%) ou superior (50\%).

Tanto para os que têm emprego como para os que não têm, depois dos 35 anos a maioria dos indivíduos não pretende ter (mais) filhos (figura 2). Dos que têm emprego, $56 \%$ pretendem permanecer sem filhos e $75 \%$ com um único filho. Já se considerarmos aqueles que não têm emprego, estas proporções aumentam para $71 \% \mathrm{e}$ $88 \%$, respetivamente.

A esmagadora maioria dos indivíduos não pretende transitar para o segundo filho, seja qual for a sua situação conjugal (figura 2). No entanto, esta proporção é mais elevada para os solteiros, divorciados ou separados $(85 \%$ e $94 \%$, respetivamente) do que para os que vivem com um cônjuge ou companheiro $(74 \%$ e $76 \%$, respetivamente). No que respeita à intenção de transitar para a parentalidade, esta tendência altera-se para os que vivem com um companheiro, dado que a maioria destes indivíduos (53\%) ainda pretende vir a ter pelo menos um filho.

À medida que os ideais aumentam, a proporção de indivíduos que pretende permanecer sem filhos ou com apenas um diminui (figura 2). Esta redução é ainda 


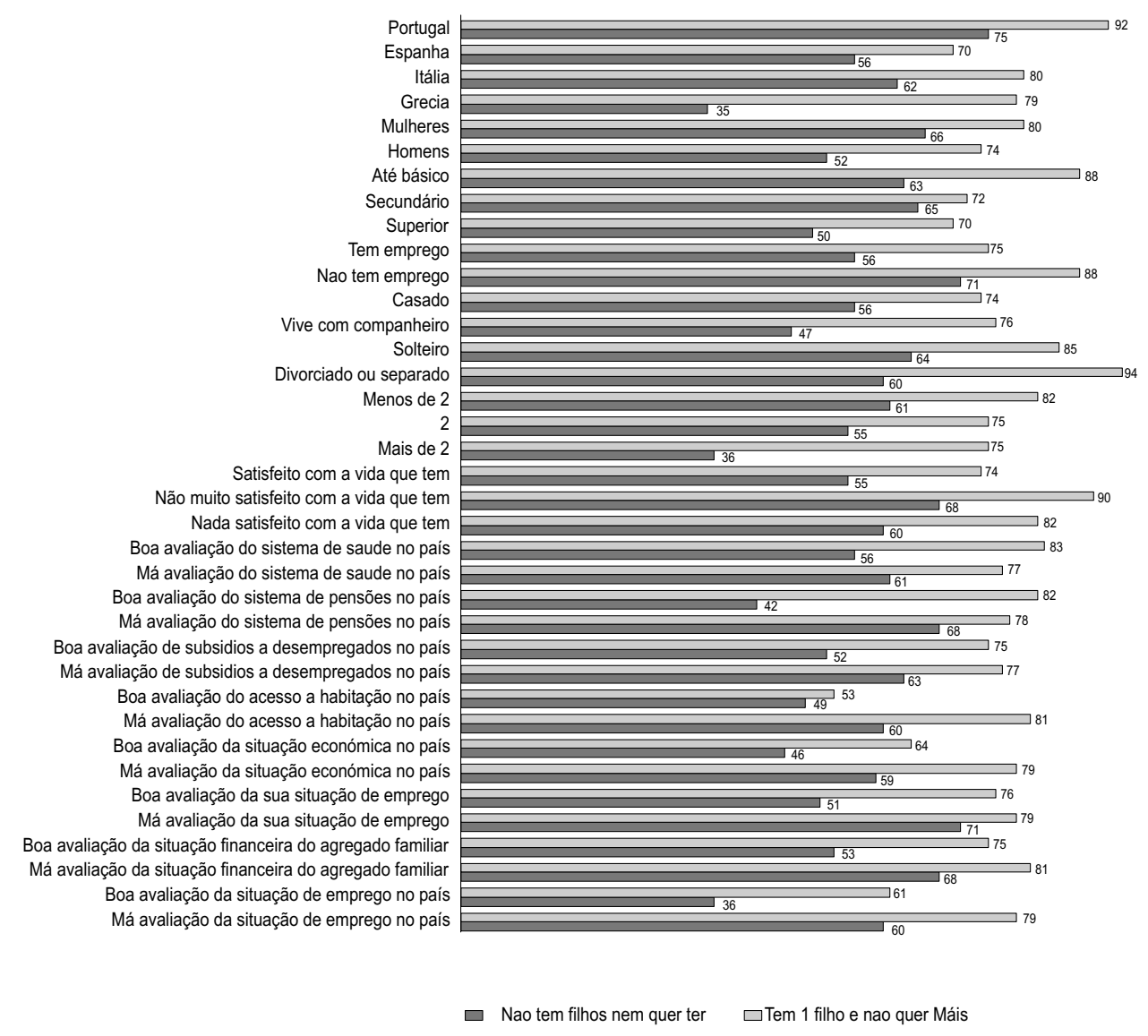

Figura 2 Proporção de indivíduos que não pretendem ter (mais) filhos depois dos 35 anos, pela situação de parentalidade, em função do país de residência, sexo, nível de escolaridade, situacão de emprego, situação conjugal, número ideal de filhos e perceções em relação à vida do indivíduo e à situação do país

mais acentuada para aqueles que não têm filhos, ou seja, é nesta paridade que o efeito do número ideal de filhos parece ser um melhor diferenciador das intenções de fecundidade.

Agrande maioria dos indivíduos que reportaram estar insatisfeitos com a sua vida em geral não pretendem transitar para a parentalidade ou para o segundo filho (figura 2). O mesmo se verifica para aqueles com perceções negativas em relação à sua vida e à situação do país. No entanto, estas proporções são mais elevadas para aqueles que já têm um filho do que para os que não têm filhos. Aliás, verificámos que esta tendência se mantém seja qual for a variável considerada. 


\section{Infecundidade depois dos 35 anos}

Para encontrar os determinantes da infecundidade nos países do Sul da Europa, recorremos a um modelo de regressão logística, considerando a variável resposta: 0 - infecundidade temporária (55\%); 1 - infecundidade permanente (45\%). Consideramos em infecundidade temporária os indivíduos que não tendo filhos demonstraram intenção de ainda vir a transitar para a parentalidade, e em infecundidade permanente aqueles que não têm filhos nem pretendem vir a tê-los.

Para o modelo multivariado ajustado (quadro 2), concluímos que tanto o país de residência como a idade e o número ideal de filhos demonstram ser os fatores com mais influência na decisão de permanecer sem filhos. Seguem-se o nível de escolaridade do próprio e a avaliação da situação de emprego do indivíduo e do sistema de pensões no seu país. As variáveis sexo, dimensão da área de residência, situação de emprego, situação conjugal e as restantes variáveis relacionadas com a perceção e expectativas futuras em relação à vida do indivíduo e à situação do país não se revelaram determinantes (pelo menos não com 95\% de confiança) para a decisão de permanecer sem filhos depois dos 35 anos.

Para perfis fixos em relação às restantes variáveis, concluímos que a idade faz depender o seu efeito do número ideal de filhos. Porém, seja para os que têm ideais iguais ou superiores a dois, como para os que têm ideais mais reduzidos, por cada ano a mais, as possibilidades de estes indivíduos se manterem sem filhos aumentam. Mesmo para aqueles com ideais mais alargados, é notório o efeito da idade, dado que um indivíduo que seja um ano mais velho do que outro tem mais $55 \%$ de possibilidades de se manter sem filhos.

Este modelo permitiu igualmente concluir que portugueses, espanhóis ou italianos têm mais possibilidades de permanecer sem filhos do que os gregos, e que os indivíduos que possuem o ensino secundário têm mais possibilidades de permanecer infecundos depois dos 35 anos do que os que têm um grau de instrução até ao básico. Já quando se comparam os indivíduos com um nível de escolaridade superior com os restantes, concluímos que não existem diferenças significativas no respeitante às suas intenções reprodutivas.

Adicionalmente, concluímos que aqueles que fazem uma má avaliação da sua situação de emprego apresentam mais possibilidades de permanecer infecundos, assim como os que fazem uma má avaliação do sistema de pensões no seu país. Por fim, concluímos que os que têm baixos ideais relativamente ao número de filhos de uma família têm mais possibilidades de permanecer infecundos do que aqueles que têm ideais mais alargados. Porém, estas diferenças atenuam-se com a idade e, a partir dos 41 anos, o número ideal de filhos deixa de ser determinante para explicar as intenções dos indivíduos.

Considerando as características potenciadoras da intenção de permanecer sem filhos depois dos 35 anos, é possível traçar o perfil mais provável daqueles indivíduos que deverão permanecer infecundos depois dos 35 anos. Na figura 3, apresentamos o perfil com probabilidade elevada de permanecer sem filhos (linha contínua), considerando os indivíduos residentes em Portugal, Espanha ou Itália que têm o ensino secundário e ideais reduzidos para o número de filhos de uma 
Quadro 2 Coeficientes estimados $(\beta)$ do modelo de regressão logística para infecundidade permanente vs. temporária, respetivos desvios-padrão estimados $(\sigma \beta)$ e valores $p$ (teste de Wald) associados (valor $p$ do teste de Hosmer $=0,61$ )

\begin{tabular}{|c|c|c|c|}
\hline Covariáveis & $\beta$ & $\sigma \beta$ & valor $p$ \\
\hline Idade & 0,44 & 0,08 & $<0,001$ \\
\hline \multicolumn{4}{|l|}{ País (ref: Portugal, Espanha e Itália) } \\
\hline Grécia & $-2,46$ & 0,82 & 0,003 \\
\hline \multicolumn{4}{|l|}{ Nível de escolaridade (ref: básico ou inferior) } \\
\hline $\begin{array}{l}\text { Secundário } \\
\text { Superior }\end{array}$ & $\begin{array}{l}1,83 \\
0,87\end{array}$ & $\begin{array}{l}0,61 \\
0,71\end{array}$ & $\begin{array}{l}0,003 \\
0,23\end{array}$ \\
\hline \multicolumn{4}{|c|}{ Número ideal de filhos para uma família (ref: 2 ou mais) } \\
\hline Menos de 2 & 12,17 & 4,22 & 0,004 \\
\hline \multicolumn{4}{|c|}{ Avaliação da situação de emprego do indivíduo (ref: boa) } \\
\hline Má & 1,78 & 0,54 & 0,001 \\
\hline \multicolumn{4}{|c|}{ Avaliação do sistema de pensões no país (ref: mau) } \\
\hline $\begin{array}{l}\text { Bom } \\
\text { Idade x número ideal de filhos (menos de 2) }\end{array}$ & $\begin{array}{l}-1,07 \\
-0,27\end{array}$ & $\begin{array}{l}0,44 \\
0,10\end{array}$ & $\begin{array}{l}0,02 \\
0,01\end{array}$ \\
\hline
\end{tabular}

Notas: Para a variável idade verificámos o pressuposto da linearidade com a função logit, tanto através do método dos quartis, como através do método dos polinómios fracionários. Agrupámos a variável "país de residência" em duas categorias (portugueses, espanhóis e italianos vs. gregos), pois através do teste de razão de verosimilhanças (TRV) concluímos que não existiam diferenças significativas entre o modelo com as categorias separadas e o modelo com as categorias agrupadas (valor $p=0,06$ ). Também agrupámos as categorias da variável "número ideal de filhos", pois através do TRV (valor $p=0,47$ ) concluímos que o coeficiente da categoria "mais de dois filhos" não diferia significativamente da referência (dois filhos). O modelo revelou um bom ajustamento aos dados, pois obtivemos um valor de $\mathrm{R}^{2}$ de Nagelkerke igual a $57 \%$ e uma capacidade discriminativa excelente $(A \cup C=0,90)$.

família (menos de dois filhos) e que fazem uma má avaliação da sua situação de emprego e do sistema de pensões no seu país, em função da idade.

Para o perfil referido, concluímos que a probabilidade de os indivíduos permanecerem sem filhos aumenta com a idade. Porém, verificamos que estas probabilidades são inferiores quando consideramos aqueles indivíduos com ideais mais alargados e com melhores perceções em relação à sua situação de emprego e ao sistema de pensões no seu país. Mantendo fixas as características sociodemográficas destes indivíduos, podemos concluir que aos 36 anos, por exemplo, um indivíduo que tenha ideais mais reduzidos e que não faça uma boa avaliação do sistema de pensões ou da sua situação de emprego tem uma probabilidade de não ter filhos muito superior $(86 \%)$ à de um indivíduo que, com a mesma idade, tenha ideais mais alargados e perceções positivas (4\%). Adicionalmente, concluímos que só a partir dos 45 anos é que não se verificam diferenças significativas entre as probabilidades destes dois grupos de indivíduos. 


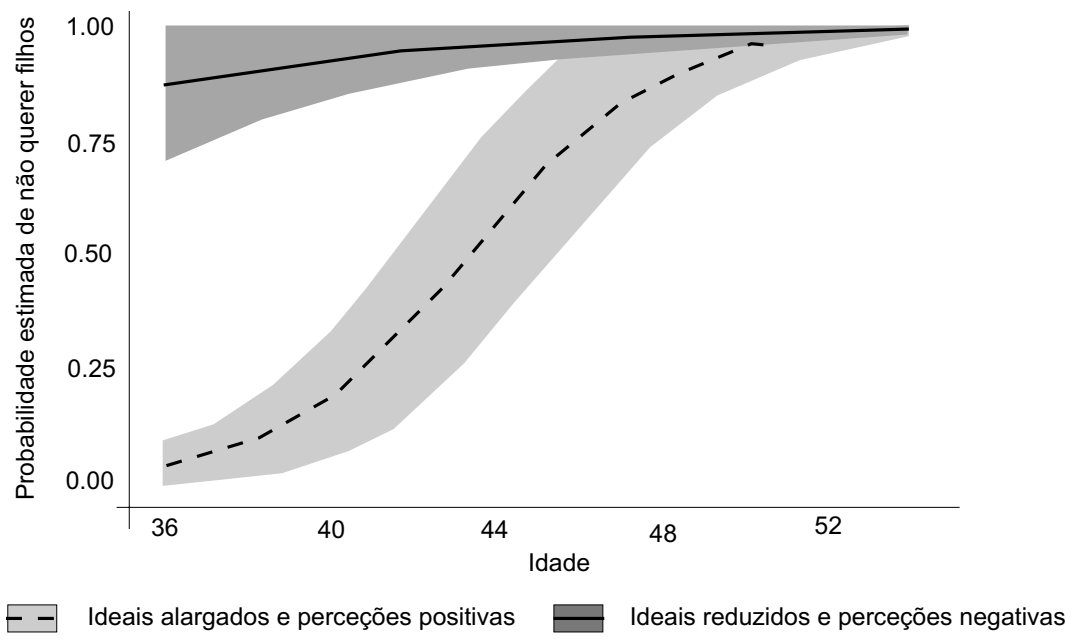

Figura 3 Perfil com probabilidade elevada de permanecer sem filhos depois dos 35 anos (as regiões a sombreado representam os respetivos intervalos de confiança a $95 \%$ )

\section{Intenção de permanecer com apenas um filho depois dos 35 anos}

Para encontrar os determinantes da intenção de permanecer com um único filho depois dos 35 anos considerámos a variável resposta: 0 - tem um filho e pretende ter mais (23\%); 1 - tem um filho e não pretende ter mais (77\%). Para o modelo multivariado ajustado (quadro 3), concluímos que uma má avaliação da situação económica no país e o facto de não ter um emprego são os principais fatores que condicionam a decisão de não transitar para o segundo filho. As variáveis idade, sexo, país de residência, nível de escolaridade do indivíduo, avaliação da sua vida em geral e do acesso à habitação e expectativas em relação a subsídios a desempregados no país, também se revelaram significativas (a menos de 5\%) para explicar a intenção de permanecer com apenas um filho, depois dos 35 anos.

Repare-se que, no que concerne à intenção de permanecer com apenas um filho, encontramos um maior número de determinantes relacionados com as perceções dos indivíduos. Se para a intenção de permanecer sem filhos depois dos 35 anos, apenas se revelam determinantes a avaliação que os indivíduos fazem da sua situação de emprego e do sistema de pensões no seu país, já no caso de permanecer com apenas um filho, passa a ser importante a perceção que os indivíduos têm da vida em geral, do acesso à habitação e da situação económica no país e as expectativas em relação aos subsídios a desempregados. Em oposição, o número ideal de filhos deixa de ser determinante quando a decisão em causa é manter-se com apenas um único filho.

Para perfis fixos em relação às restantes variáveis, podemos concluir que por cada ano a mais, as possibilidades de estes indivíduos não quererem transitar para o segundo filho aumentam cerca de $38 \%$. Este modelo também permitiu concluir 
Quadro 3 Coeficientes estimados $(\beta)$ do modelo de regressão logística para a decisão permanente de ter um filho vs. temporária, respetivos desvios-padrão estimados $(\sigma b)$ e valores $p$ (teste de Wald) associados (valor $p$ do teste de Hosmer $=0,76$ )

\begin{tabular}{llrl}
\hline Covariáveis & $\beta$ & $\sigma \beta$ & Valor $p$ \\
\hline Idade & 0,32 & 0,05 & $<0,001$ \\
\hline $\begin{array}{l}\text { Sexo (ref: homens) } \\
\text { Mulheres }\end{array}$ & 1,08 & 0,43 & 0,01 \\
\hline $\begin{array}{l}\text { País (ref: Portugal e Itália) } \\
\text { Grécia e Espanha }\end{array}$ & $-1,56$ & 0,46 & $<0,001$ \\
\hline $\begin{array}{l}\text { Nível de escolaridade (ref: básico ou inferior) } \\
\text { Secundário }\end{array}$ & $-1,29$ & 0,51 \\
Superior & $-0,97$ & 0,61 & 0,011 \\
\hline $\begin{array}{l}\text { Situação de emprego (ref: tem emprego) } \\
\text { Não tem emprego }\end{array}$ & 1,78 & 0,01 \\
\hline $\begin{array}{l}\text { Em geral, como se sente em relação à vida que tem? (ref: satisfeito) } \\
\text { Não satisfeito }\end{array}$ & 1,12 & 0,67 & 0,047 \\
\hline $\begin{array}{l}\text { Avaliação do acesso à habitação no país (ref: má) } \\
\text { Boa }\end{array}$ & $-1,39$ & 0,56 & 0,02 \\
\hline $\begin{array}{l}\text { Avaliação da situação económica do país (ref: má) } \\
\text { Boa }\end{array}$ & $-1,93$ & 0,81 \\
\hline $\begin{array}{l}\text { Expectativas em relação a subsídios a desempregados no país } \\
\text { ref: melhor ou na mesma) }\end{array}$ & & 0,02 \\
\hline Pior & 1,28 & 0,45 & 0,005 \\
\hline
\end{tabular}

Notas: Para a variável idade verificamos o pressuposto da linearidade com a função logit, tanto através do método dos quartis, como através do método dos polinómios fracionários. Agrupámos a variável país em duas categorias: Portugal e Itália vs. Grécia e Espanha, pois os coeficientes correspondentes do modelo de regressão logística não eram significativamente diferentes entre si (valores p do TRV iguais a 0,41 e 0,40, respetivamente). O modelo de regressão logística ajustado revelou um bom ajustamento aos dados, pois obtivemos um valor de $\mathrm{R}^{2}$ de Nagelkerke igual a $51 \%$ e uma boa capacidade discriminativa $(A \cup C=0,89)$.

que as mulheres têm mais possibilidades de não transitar para o segundo filho do que os homens, assim como os portugueses e italianos em relação aos espanhóis e aos gregos.

Os que possuem um grau de instrução até ao ensino básico têm mais possibilidades de não transitar para o segundo filho do que os que têm o ensino secundário. No entanto, também neste caso, quando se comparam os que têm o ensino superior com os que têm níveis de escolaridade mais baixos, concluímos que não existem diferenças significativas entre as suas intenções reprodutivas.

Adicionalmente, concluímos que os que não têm emprego têm mais possibilidades de não transitar para o segundo filho, assim como os que não se sentem satisfeitos com a sua vida em geral e os que fazem uma má avaliação do acesso à habitação e da situação económica do seu país. Finalmente, os que têm piores expectativas em relação aos subsídios a desempregados no seu país têm mais possibilidades de permanecer com apenas um filho.

Na figura 4, apresentamos o perfil com probabilidade elevada da intenção de não transitar para o segundo filho (linha contínua), no qual consideramos mulheres, portuguesas ou italianas, com ensino até ao básico, que não têm emprego, que 


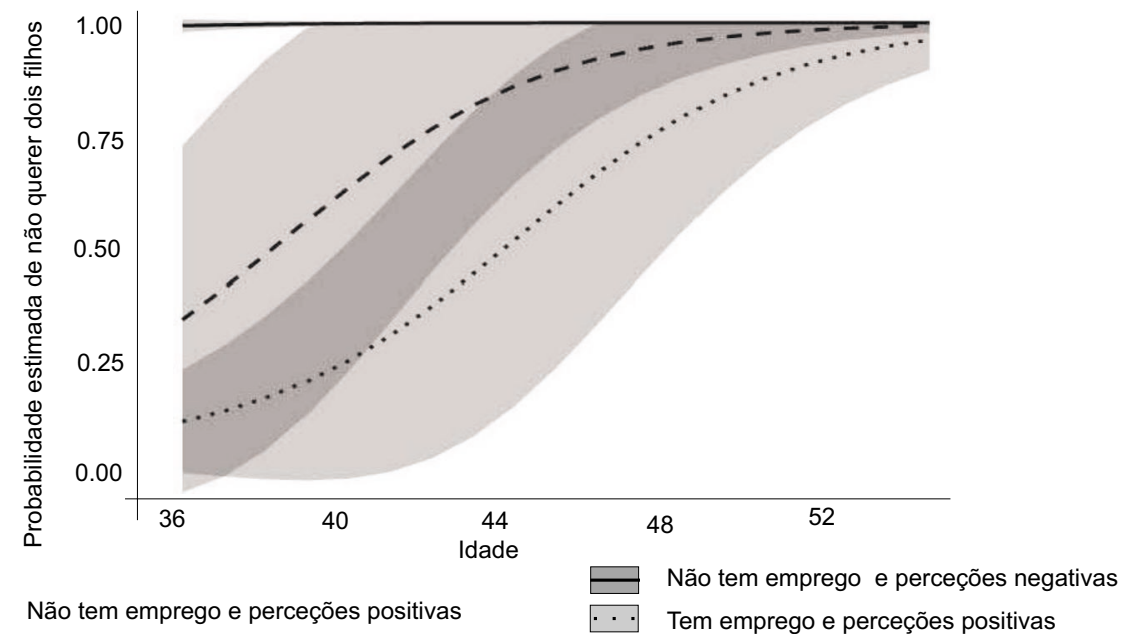

Figura 4 Perfil com probabilidade elevada da decisão permanente de não transitar para o segundo filho depois dos 35 anos (as regiões a sombreado representam os respetivos intervalos de confiança a $95 \%$ )

não estão satisfeitas com a sua vida em geral, que fazem uma má avaliação do acesso à habitação e da situação económica do país e que têm piores expectativas em relação a subsídios a desempregados no país, em função da idade. Para este perfil, concluímos que a probabilidade de os indivíduos não transitarem para o segundo filho é praticamente igual a 1 , seja qual for a idade considerada. Porém, ao variar as perceções dos indivíduos em relação à sua vida e ao estado do país (i.e., considerando as mulheres que estão satisfeitas com a sua vida em geral, que fazem uma boa avaliação do acesso à habitação e da situação económica do país e que têm melhores ou as mesmas expectativas em relação aos subsídios a desempregados no país), concluímos que as probabilidades de estas mulheres permanecerem com apenas um filho são consideravelmente inferiores, principalmente para as mais jovens. Se, para além de considerarmos perceções positivas, fizermos variar a situação de emprego, verificamos que estas probabilidades são ainda mais baixas, seja qual for a idade considerada.

Mantendo fixas as características sociodemográficas destas mulheres, concluímos que uma mulher com 36 anos que tenha emprego e que faça uma avaliação positiva da sua vida em geral, do acesso à habitação, da situação económica do seu país e que tenha melhores expectativas em relação aos subsídios de desemprego no seu país, apresenta uma probabilidade de não transitar para o segundo filho muito baixa $(7 \%)$. Já para uma mulher com a mesma idade e que, apesar de ter perceções positivas, não tenha emprego, essa probabilidade é igual a 31\%, e é igual a $99 \%$ se as suas perceções forem negativas e se não tiver emprego. 


\section{Considerações finais}

Os resultados destes modelos permitem identificar fatores potenciadores da infecundidade e da fecundidade tardia. Concluímos que a idade é um fator comum em ambos os estudos efetuados. Depois dos 35 anos, o aumento da idade potencia a decisão de não ter filhos ou de não ter o segundo filho. Desta forma, a idade assume um papel extremamente importante nas intenções reprodutivas destes indivíduos, confirmando-se que aqueles que atingem idades mais avançadas sem ter filhos são mais propensos a não vir a transitar para a parentalidade (Morgan, 1991).

O país de residência dos indivíduos é determinante para explicar as intenções destes indivíduos. Os gregos são os que têm menos possibilidades de permanecer sem filhos ou de permanecer com apenas um filho depois dos 35 anos (neste último caso, a par dos espanhóis). Em oposição, temos os portugueses, espanhóis e italianos, que são mais suscetíveis de permanecer sem filhos.

Nos países do Sul da Europa, o estado civil deixou de ser um preditor importante dos níveis de fecundidade (Kohler, Billari e Ortega, 2006), dado que a coabitação se tem tornado uma escolha comum para a primeira união e a sua importância tem vindo a aumentar (Sobotka, 2008). Os resultados mostram que, para a decisão de permanecer sem filhos ou com apenas um filho, os casados apresentam o mesmo comportamento dos que vivem em coabitação, contudo estes não se distinguem dos solteiros ou dos divorciados ou separados. Deste modo, para os que têm mais de 35 anos, a situação conjugal não é determinante para explicar a intenção de não ter filhos ou de não transitar para o segundo filho.

Concluímos que o nível de escolaridade continua a ser um fator central nas intenções reprodutivas. Se os baixos índices de fecundidade e o adiamento na idade de entrada na parentalidade estão associados a níveis de escolaridade mais elevados (Kohler, Billari e Ortega, 2006; Testa, 2012), quando consideramos os indivíduos mais velhos que têm apenas um filho, aqueles que têm níveis de escolaridade um pouco mais elevados são menos suscetíveis de permanecer com apenas um filho. E nas idades mais avançadas que aqueles indivíduos que adiaram os seus projetos de fecundidade, devido ao tempo que levaram a concluir os seus estudos ou a estabilizar-se no mercado de trabalho (Kohler, Billari e Ortega, 2006), têm uma oportunidade de vir a realizar as suas intenções reprodutivas. Efetivamente, segundo Fagan, Patterson e Vanderplas (2011), os elevados níveis de educação não diminuem o desejo de ter filhos, pelo contrário, a intenção aumenta para as mulheres que têm níveis de educação mais elevados. Em oposição, temos aqueles que chegaram aos 35 anos sem filhos, sendo neste caso os que têm o secundário que apresentam mais possibilidades de não quererem transitar para a parentalidade relativamente aos que detêm um grau de instrução inferior. Uma razão para tal, pode estar associada ao facto de estes indivíduos, que adiaram o nascimento do primeiro filho, terem agora uma maior dificuldade (falta de recursos) em suportar os custos da entrada na parentalidade, principalmente, em contextos onde a parentalidade se tem instituído com requisitos cada vez mais exigentes (Sobotka, 2008).

Segundo Kohler, Billari e Ortega (2006), a entrada dos mais jovens no mercado de trabalho tem sido difícil e os países da Europa com taxas de desemprego mais 
elevadas são os que apresentam índices de fecundidade mais baixos. Adicionalmente, o elevado nível de incerteza económica destes países reforça o adiamento dos projetos de fecundidade (Kohler, Billari e Ortega, 2006; Fagan, Patterson e Vanderplas, 2011). Efetivamente, os pais que estão sujeitos a incertezas financeiras, tendem a limitar o número de filhos (Adsera, 2005) perante a ponderação entre custos e benefícios de ter um ou mais filhos (Kohler, Billari e Ortega, 2006).

Com este estudo concluímos que uma maior instabilidade financeira condiciona as intenções de fecundidade dos sul-europeus. Seja pelo facto de não terem um trabalho, da má avaliação da sua situação de emprego e da situação económica do seu país ou pelas piores expectativas que têm em relação ao nível de subsídios a desempregados no seu país. A verdade é que, em ambos os estudos, as decisões destes indivíduos são condicionadas pela sua situação de emprego ou pela perceção que têm em relação à sua vida e à situação do país. Estas questões são ainda mais importantes quando a decisão em causa é transitar para o segundo filho. Repare-se que as possibilidades de estes indivíduos permanecerem com apenas um filho são mais elevadas para aqueles que: (1) não têm um trabalho; (2) fazem uma má avaliação da situação económica do país; e (3) têm piores expectativas em relação aos subsídios de desemprego. Concomitantemente, maiores possibilidades de permanecer sem filhos estão associadas à má avaliação da situação de emprego dos indivíduos.

A avaliação que os indivíduos fazem do acesso à habitação também é importante para explicar as suas intenções reprodutivas. Concluímos que aqueles que fazem uma má avaliação têm mais possibilidades de não transitar para o segundo filho depois dos 35 anos. Se considerarmos que os mercados de arrendamento restritos e que a sobrevalorização do mercado imobiliário nos países do Sul da Europa fazem com que os indivíduos saiam mais tarde da casa dos pais (Kohler, Billari e Ortega, 2006), então é de esperar que piores condições no acesso à habitação potenciem o adiamento da entrada na parentalidade.

Outras variáveis, como a avaliação do sistema de pensões e a perceção da vida dos indivíduos em geral, também se revelaram significativas para explicar as suas intenções reprodutivas. Concluímos que aqueles que fazem piores avaliações do sistema de pensões no seu país são mais propensos a permanecer sem filhos depois dos 35 anos. Estes resultados são um indício de que o sistema de pensões pode estar a ganhar uma maior importância nos países onde o efeito da crise económica e financeira é mais acentuado.

O número de filhos considerado ideal para uma família, também surge como um fator essencial para as intenções reprodutivas destes indivíduos. Concluímos que os indivíduos com ideais reduzidos têm mais possibilidades de não transitar para a parentalidade depois dos 35 anos. São diversos os estudos que apontam para o facto de a dimensão ideal no respeitante ao número de filhos de uma família ser um dos principais determinantes do comportamento reprodutivo (Sobotka e Beaujouan, 2014; Testa e Grilli, 2006, 2012). Uma vez que são os que têm baixos ideais os mais suscetíveis a permanecer sem filhos, verificamos que um possível declínio deste valor pode contribuir para agravar os baixos índices de fecundidade (Sobotka e Beaujouan, 2014). 
Os resultados deste estudo, permitem mostrar que, para além das características sociodemográficas dos indivíduos, é necessário ter em consideração um conjunto de valores, perceções e expectativas que determinam as suas intenções reprodutivas, nomeadamente perceções da estabilidade económica do indivíduo e/ou do país. Para além disso, estes fatores são ainda mais importantes quando a decisão em causa é transitar ou não para um segundo filho.

De uma forma geral, concluímos que o aumento do nível de escolaridade ou uma maior estabilidade laboral podem ser potenciadores da decisão destes indivíduos de tencionarem ter um ou mais filhos. Adicionalmente, se as perceções destes indivíduos em relação à sua vida e à situação do seu país forem positivas, então estamos perante uma redução considerável das probabilidades dos sul-europeus permanecerem sem filhos ou com apenas um único filho.

\section{Referências bibliográficas}

Adsera, Alicia (2005), “Where are the babies? Labour market conditions and fertility in Europe", European Journal of Population, 27, pp. 1-32.

Ajzen, Icek (1991), "The theory of planned behaviour", Organizational Behavior and Human Decision Processes, 50 (2), pp. 179-211.

Ajzen, Icek, e Jane Klobas (2013), “Fertility intentions: an approach based on the theory of planned behavior", Demographic Research, 29 (8), pp. 203-232.

Cunha, Vanessa (2012), “Trajetórias não reprodutivas em três gerações de portugueses: incidência, circunstâncias, oportunidade", Atas do VII Congresso Português de Sociologia. Sociedade, Crise e Reconfigurações, Porto, pp. 1-11.

Fagan, Patrick, Elise Patterson, e Samuel Vanderplas (2011), “Factors in fertility decline: why fertility is falling, and how to raise it", Working Paper 202.393.2100, Family Research Council.

Hosmer David, e Stanley Lemeshow (2013), Applied Logistic Regression, Nova Iorque, Wiley (3. ํㅜ edição).

Kohler, Hans-Peter, Francesco Billari, e José Antonio Ortega (2006), “Low fertility in Europe: causes, implications and policy options", em F. R. Harris (org.), The Baby Bust. Who Will Do the Work? Who Will Pay the Taxes?, Lanham, MD, Rowman \& Littlefield, pp. 1-51.

Mendes, Maria Filomena (2012), “Declínio da fecundidade, adiamento e número ideal de filhos em Portugal: o papel das medidas de política", em Conferência "Nascer em Portugal, Roteiros do Futuro", Imprensa Nacional Casa da Moeda, pp. 91-110.

Morgan, S. Philip (1991), "Late Nineteenth and early Twentieth-Century childlessness", American Journal of Sociology, 97 (3), pp. 779-807.

Sobotka, Tomas (2008), “Overview Chapter 6: The diverse faces of the Second Demographic Transition in Europe", Demographic Research, 19, pp. 171-224.

Sobotka, Tomas, e Eva Beaujouan (2014), "Two is best? The persistence of two-child family ideal in Europe", Vienna Institute of Demography Working Paper, 3. 
Testa, Maria Rita (2012), “Family sizes in Europe: evidence from the 2011 Eurobarometer Survey", European Demographic Research Paper, 2, Vienna Institute of Demography of the Austrian Academy of Sciences, pp. 1-100.

Testa, Maria Rita, e Leonardo Grilli (2006), “The influence of childbearing regional contexts on ideal family size in Europe", Population, 61 (1), pp. 99-127.

\section{Agradecimentos}

Agradecemos à doutora Vanessa Cunha, coordenadora do projeto no qual este estudo se insere - "The Double Postponement. Men and Women Coping with Childbearing Intentions in Their Late 30s and Early 40s" - pelos seus importantes comentários e sugestões, tanto no decorrer da análise dos resultados como na elaboração do relatório final deste estudo.

Rita Freitas. Investigadora, Cidehus, Universidade de Évora.

E-mail: rfreitas@uevora.pt

Maria Filomena Mendes. Professora associada do Departamento de Sociologia e investigadora, Cidehus, Universidade de Évora. E-mail: mmendes@uevora.pt

Andreia Maciel. Investigadora, Cidehus, Universidade de Évora.

E-mail: amaciel@uevora.pt

Receção: 12 de setembro de 2016 Aprovação: 03 de março de 2017 
